\title{
ANALISIS REAKSI PASAR SEBELUM DAN SESUDAH PENGUMUMAN AKUISISI DI BURSA EFEK INDONESIA (BEI)
}

\author{
I Kadek Redy Irawan ${ }^{1}$ \\ Ica Rika Candraningrat ${ }^{2}$ \\ ${ }^{1,2}$ Fakultas Ekonomi dan Bisnis Universitas Udayana (Unud), Bali Indonesia \\ email: redy.irawan97@gmail.com
}

\begin{abstract}
ABSTRAK
Akuisisi merupakan sebuah kebijakan atau strategi yang bertujuan untuk melakukan perluasan usaha dengan mengambil alih kepemilikan perusahaan lain. Motif perusahaan dalam melakukan akuisisi akan berdampak pada reaksi pasar yang positif ataupun negatif. Perusahaan yang melakukan akuisisi dengan motif ekonomi akan direaksi positif oleh pasar, sedangkan motif non ekonomi akan direaksi negatif oleh pasar. Menguji perbedaan reaksi pasar sebelum dan sesudah pengumuman akuisisi yang dicerminkan dengan rata-rata abnormal return dalam periode lima hari sebelum dan lima hari sesudah pengumuman akuisisi merupakan tujuan dari penelitian ini. Metode pengambilan sampel menggunakan teknik purposive sampling dan menghasilkan 55 sampel perusahaan yag melakukan akuisisi di Bursa Efek Indonesia. Teknik yang digunakan adalah uji wilcoxon signed rank test. Hasil yang ditemukan bahwa tidak terdapat perbedaan reaksi pasar yang signifikan sebelum dan sesudah pengumuman akuisisi. Penyebab utama hal ini bisa terjadi adalah karena ketidaktahuan investor akan motif perusahaan melakukan akuisisi, sehingga investor ragu dalam mengambil keputusan investasi
\end{abstract}

Kata kunci: abnormal return, akuisisi, efisiensi pasar, rata-rata abnormal return.

\begin{abstract}
Acquisition is a policy or strategy that aims to expand its business by taking over ownership of another company. The motive of the company in making an acquisition would have a positive or negative market reaction. Companies that made acquisitions with economic motives would be reacted positively by the market, while non-economic motives would be negatively reacted by the market. Examined the differences in market reaction before and after the announcement of the acquisition which was reflected by the average abnormal return in the period of before and after five days the announcement of the acquisition is the purpose of this study. The sampling method used a purposive sampling technique and produced 55 samples of companies that made acquisitions on the Indonesia Stock Exchange. The technique used was the Wilcoxon signed rank test. The results found that there were no significant differences in market reaction before and after the acquisition announcement. The main reason this could happen was because of investors' ignorance of the company's motives for acquisitions, therefore investors were hesitant in making investment decision.
\end{abstract}

Keyword:, abnormal return, acquisition, efficiency market, average abnormal return. 


\section{PENDAHULUAN}

Undang-undang No 8 Tahun 1995 menjelaskan bahwa pasar modal adalah suatu kegiatan yang bersangkutan dengan penawaran umum dan perdagangan efek, perusahaan publik yang berkaitan dengan efek yang diterbitkannya, serta lembaga dan profesi yang berkaitan dengan efek.. Peranan pasar modal untuk perekonomian di setiap negara sangatlah besar, hal ini disebabkan lantaran pasar modal mampu dimanfaatkan sebagai media perantara bagi perusahaan dengan investor, sehingga penanaman modal dalam suatu perusahaan mampu dilakukan oleh investor untuk memperoleh return yang maksimal dan disisi lain perusahaan juga diuntungkan dengan dana yang diinvestasikan oleh investor. Upaya yang dapat dilakukan investor untuk mendapatkan dana di pasar modal adalah dengan cara menerbitkan obligasi ataupun dengan menerbitkan saham yang merupakan instrumen paling menarik untuk di investasikan. Ketertarikan investor untuk menginvestasikan dananya pada instrumen saham, mengakibatkan investor harus lebih memperhatikan informasi-informasi yang dapat memengaruhi harga saham. Kondisi yang dapat memengaruhi naik turunnya harga saham adalah, kondisi makro ekonomi, , risiko sistematis, pergantian direksi secara tiba-tiba, kinerja serta kebijakan perusahaan, kondisi mikro ekonomi dan juga kondisi dari efek psikologi pasar (Fahmi, 2012:276). Informasi yang bersifat perkiraan atau informasi masa yang akan datang, peristiwa yang telah dipublikasikan tetapi belum dilaksanakan, serta informasi yang sifatya historis dapat menggambarkan harga saham di pasar modal (Wiagustini, 2014:239). Kandungan informasi yang terdapat pada suatu peristiwa akan memberikan dampak pada pasar modal sehingga investor akan merespon dengan melakukan sebuah investasi.

Cepatnya sebuah informasi baru dan mencermikan harga sekuritasnya, menandakan bahwa pasar modal akan semakin efisien (Tandelilin, 2010:219). Fama (1970) dalam Jogiyanto (2017:631) menyatakan bahwasanya efisiensi pasar dapat diklasifikasikan kedalam tiga bentuk efisiensi pasar yaitu kuat., setengah kuat danlemah. Informasi yang mengakibatkan pasar bereaksi dapat berupa informasi yang dikeluarkan oleh pemerintah berupa kondisi politik dan ekonomi, regulasi tentang perubahan peraturan industri tertentu, ataupun informasi yang bersumber dari perusahaan yang berupa kebijakan untuk mengembangkan perusahaan tersebut seperti pengumuman pergantian pemimpin, , akuisisi dan merger, pengumuman pembagian dividen, pergantian metode akuntansi, pengembangan produk baru, pengumuman laba, pemecahan saham dan kebijakan-kebijakan yang lain sebagainya.

Salah satu contoh sumber informasi dari perusahaan adalah publikasi merger dan akuisisi, yang diharapkan mampu membuat pasar bereaksi. Secara terminologi merger juga akuisisi terlihat sama, akan tetapi sebenarnya merger dan juga akuisisi mengadung arti yang berbeda. Merger secara umum ialah penggabungan diantara dua ataupun lebih perusahaan, yang mempertahankan satu perusahan saja. Berbeda halnya dengan akuisisi yang merupakan pengambilalihan kepemilikan perusahaan satu dengan perusahaaan lainnya, hanya saja perusahaan target akan tetap dipertahankan. Alasan yang mendasari perusahaan melakukan akuisisi adalah untuk mempercepat perkembangan perusahaan sehingga akan memberikan sinergi operasional dan finansial (Wiagustini, 2014:317). Sinergi operasional didapat dari 
perusahaan yang melakukan perluasan usaha pada sektor bisnis yang sama sehingga mampu meminimalisir biaya rata-rata karena biaya tetap persatuannya berkurang, sedangkan sinergi finansial dapat menekan pembayaran pajak karena akuisisi akan mengurangi risiko, sehingga rasio hutang yang lebih tinggi dapat digunakan oleh perusahaan. Penggunaan hutang yang lebih tinggi dapat menimbulkan penghematan pajak yang cukup besar dikemudian hari, selama pembayaran bunga masih bersifat tax deductible.

Informasi pengumuman akuisisi dianggap memberi dampak positif terhadap reaksi pasar apabila dilakukan dengan motif ekonomi yang erat kaitanya dengan maksud perusahaan dalam meningkatkan keuntungan pemegang saham atau memaksimalkan nilai perusahaan, motif ini biasanya dilakukan pada perusahaan target yang memiliki keunggulan kompetitif, dan dipercaya dapat menciptakan sebuah sinergi sesuah digabung. Peningkatan volume penjualan dan laba perusahaan juga dipercaya dapat menjadi bentik sinergi yang diciptakan dalam jangka panjang. Strategi akuisisi juga bisa dianggap negatif apabila dilakukan pada perusahaan dengan motif non ekonomi yang erat kaitanya dengan keinginan subyektif, ambisi ataupun ego pribadi manajer ataupun pemilik perusahaan, motif ini biasanya dilakukan pada perusahaan yang memiliki kondisi yang lemah secara keterampilan manajemen dan modal, berambisi menjadi organisasi yang paling besar di dunia walaupun dalam penggabungan usaha tersebut dimungkinkan tidak akan menciptakan keuntungan karena diambil alih dengan pihak bank. Strategi akuisisi pada dasarnya dilakukan untuk kebaikan perusahaan sehingga nantiya pasar akan bereaksi positif terhadap pengumuman akuisisi. Adnyani dan Gayatri (2018) berpendapat bahwa akuisisi sangat erat kaitannya dengan teori sinyal yang dapat dikatakan sebagai hasil dari corporate action, yaitu sebuah kebijakan yang diambil oleh perusahaan untuk membenahi kinerja perusahaan baik dalam jangka panjang ataupun jangka pendek. Akuisisi menjadi salah satu kebijakan yang dapat membantu perusahaan dalam memperbaiki kinerja perusahaannya.

Aktivitas merger dan akuisisi pada dasarnya bukanlah sebuah hal yang baru didalam dunia bisnis lantaran aktivitas ini sudah marak terjadi di Negara Eropa dan di Negara Amerika Serikat tepatnya pada tahun 1960-an. Sejalan dengan berkembangan era teknologi informasi komunikasi reformasi, dan transparansi di Indonesia sejak tahun 1998, hingga strategi terkait dengan mengembangan usaha yaitu merger dan akuisisi di Indonesia mulai berkembang pesat. Reuters (2014) menyatakan bahwa Indonesia merupakan negara yang memiliki sebuah potensi dengan pergerakan nilai merger dan akuisisi yang memperoleh peningkatan sebesar 16,7 persen setelah terjadinya krisis tahun 1998 dan tahun 2008. Kenaikan tersebut dapat artikan sebagai ukuran bahwasanya investor sudah mulai memprioritaskan Indonesia sebagai destinasi investasi sehingga dapat memberikan efek yang positif bagi perekonomian Indonesia. Kondisi tersebut diprakirakan akan terus meningkat hingga 10 tahun yang akan datang (2016-2025) akibat efek spin off dari kebijakan yang dikeluarkan oleh Pemerintah Jokowi - Jusuf Kalla yang sangat mendukung penuh perkembangan perusahaan- perusahaan kecil menengah di Indonesia (Tarigan et al., 2016). 
Komisi Pengawas Persaingan Usaha (KPPU) mencatat selama lima tahun terakhir tepatnya pada tahun 2014-2018 terdapat 335 notifikasi perusahaan yang menggunakan strategi akuisisi untuk megembangkan usahanya.

Tabel 1.

Perkembangan Akuisisi di Indonesia Tahun 2014-2018

\begin{tabular}{cc}
\hline Tahun & Akuisisi \\
\hline 2014 & 55 \\
2015 & 51 \\
2016 & 65 \\
2017 & 90 \\
2018 & 74 \\
Jumlah & 335 \\
\hline
\end{tabular}

Sumber :kppu.go.id, 2019

Tabel 1. menjelaskan bahwa aktivitas akuisisi di Indonesia selama lima tahun terakhir (2014-2018) mengalami peningkatan sampai tahun 2017 yaitu sebanyak 90 perusahaan. Angka tersebut menunjukan peningkatan yang signifikan dari tahun 2016 yaitu 65 perusahaan yang melaporkan aktivitas akuisisinya. Tren akuisisi nyatanya tidak berlanjut ditahun berikutnya karena di tahun 2018 hanya tercatat 74 perusahaan saja yang melaporkan aktivitas akuisisinya ke KPPU. Penurunan tersebut diduga karena masa transisi kepengurusan KPPU serta banyaknya perusahaan yang melakukan akuisisi namun tidak melapor kepada pihak yang bersangkutan.

Fenomena yang terjadi terkait dengan aktivitas akuisisi mengakibatkan investor harus mampu menganalisis informasi pengumuman akuisisi dengan tepat agar nantinya dapat memberikan return yang maksimal. Pengujian yang dapat dilakukan untuk megetahui reaksi pasar dari pengumuman akuisisi adalah dengan melakukan pengujian efisiensi pasar semi strong, selain itu pengujian kandungan informasi juga diperlukan dalam mengetahui sebuah reaksi pasar yang terjadi dari adanya informasi akuisisi yang dikeluarkan oleh perusahaan. Abnormal return yang berbeda dari pengumuman akuisisi dapat menjadi indikator terjadinya reaksi pasar. Kelebihan yang diperoleh dari sebuah return aktual dibandingkan dengan return ekspektasi.disebut dengan abnormal return. Abnormal return dapat dijadikan indikator utama untuk menunjukan reaksi pasar dari sebuah pengumuman karena diukur dengan tingkat keuntungan menggunakkan return sebagai perubahaan dari harga (Munthe, 2016).

Pengujian terhadap adanya sebuah kandungan informasi yang terdapat dalam publikasi merger dan akuisisi sudah diuji oleh para peneliti sebelumnya. Hasil yang di dapatkan bahwa publikasi merger dan akuisisi mempunyai sebuah kandungan informasi sehingga mengakibatkan pasar bereaksi. Penelitian sebelumnya seperti: Adnyani (2018) Simarmata dan Saifi (2018), Singhvi dan Patel (2016), Elad dan Bongbee (2017), Rani et al. (2015), Diaw (2014), Tarabay dan Hammoud, (2017) serta Kariuki et al. (2016), mendapatkan perolehan hasil positif atau dengan kata lain menandakan adanya perbedaan reaksi pasar yang signifikan dan reaksi tersebut diproksikan dengan abnormal return dari pengumuman akuisisi. 
Peneliti lainnya justru menemukan hasil yang bertolak belakang, dimana Adnan dan Hossain (2016), Dananjaya dan Wiagustini (2015), Malau dkk. (2017), Devarajappa S (2018), Larasati dan Wirama (2018), Andriani dan Purbawangsa (2016), Israil dan Khan (2016), Geekiyanage dan Jahfer (2017) dan juga Rahman et al. (2018) mendapatkan hasil negatif atau tidak adanya perbedaan reaksi pasar yang signifikan dan reaksi tersebut diproksikan dengan abnormal retun dari pengumuman akuisisi. Hasil penelitian yang telah diuraikan sebelumnya, menunjukan adanya inkonsistensi hasil penelitian mengenai reaksi pasar yang terjadi dari pengumumann merger dan akuisisi. Inkonsistensi yang terdapat dalam penelitian-penelitian sebelumnya disebabkan karena faktor yang digunakan dalam satu penelitian tidak terbukti apabila di terapkan dalam penelitian lainnya

Pasar pada dasarnya akan menimbulkan sebuah reaksi akibat dari adanya pengumuman akuisisi yang diproksikan dengan adanya abnormal return. Sinyal positif atau negatif dari pengumuman akuisisi akan berdampak pada reaksi pasar yang positf atau negatif pula. Peneliti yang memperkuat pernyataan tersebut adalah Adnyani dan Gayatri (2018) yang penilitiannya menggunakan 50 sampel perusahaan menghasilkan adanya perbedaan reaksi pasar yang signifikan dan reaksi tersebut diproksikan dengan abnormal return pada perusahaan pengakuisisi.

Singhvi dan Patel (2016) menyatakan bahwa pengumuman merger memperoleh abnormal return positif signifikan. Elad dan Bongbee (2017) dan Rani et al. (2015) menunjukan hasil abnormal return positif signifikan pada di hari pengumuman merger dan akuisisi yang diproksikan dari adanya abnormal return.

Kariuki et al. (2016) yang meneliti tentang reaksi pasar akibat adanya publiksi akuisisi ataupun merger pada 30 perusahaan di tiga negara Afrika Timur, yaitu Kenya, Uganda dan Tanzania juga memperoleh hasil adanya reaksi pasar yang signifikan dan reaksi tersebut diproksikan dengan abnormal return selama event window. Komulatif rata-rata abnormal return mengungkapkan bahwa perusahaan akuisitor memperoleh pengembalian positif segera setelah pengumuman akuisisi. Namun, kinerja positif itu berumur pendek, empat hari sesudah dipublikasikannya pengumuman merger ataupun akuisisi.

Tarabay dan Hammoud (2017) yang meneliti tentang abnormal return terhadap pengumuman akuisisi pada pasar Kuwait menemukan adanya reaksi pasar yang signifikan akibat adanya pengumuman akuisisi dan reaksi tersebut diproksikan dengan abnormal return yang positif di perusahaan-perusahaan target. Hasil serupa ditemukan oleh Simarmata dan Saifi (2018) serta Diaw (2014), Mengacu dari bukti empiris tersebut maka hipotesis penelitian yang digunakan yaitu:

$\mathrm{H}_{1}$ : Terdapat perbedaan reaksi pasar sebelum dan sesudah pengumuman akuisisi.

$\mathrm{H}_{1}$

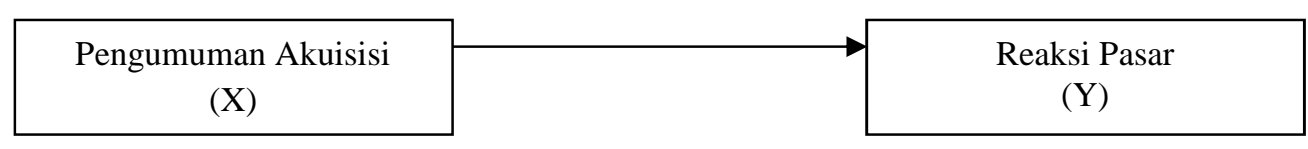

Gambar 1. Kerangka Konseptual 
Gambar 1. menjelaskan bahwa variabel yang digunakan adalah pengumuman akuisisi dan reaksi pasar. Variabel independen (X) ialah pengumuman akuisisi dan variabel dependen (Y) ialah reaksi pasar. Indikator dalam pengukuran reaksi pasar ialah dengan memakai abnormal return.

\section{METODE PENELITIAN}

Pengujian sebuah kandungan informasi dari pengumuman akuisisi disekitar tanggal peristiwa dapat menggunakan pendekatan studi peristiwa. Periode pengamatan menggunakan rentang waktu sebelas hari pengamatan (lima hari sebelum diumumkanya akuisisi, hari $\mathrm{H}$ diumumkannya akuisisi serta lima hari sesudah diumumkanya akuisisi). Pemilihan rentang waktu sebelas hari diharapkan agar nantiya dapat menggambarkan abnormal return dari pengumuman akuisisi secara akurat tanpa adanya dampak yang disebabkan oleh aksi korporasi selain akuisisi.

Bursa Efek Indonesia menjadi lokasi atau tempat dilakukannya penelitian, khususnya perusahaan-perusahaan yang melaksanakan aktivitas akuisisi periode 2014-2018, dimana data yang diperoleh melalui www.idx.co.id dan www.kppu.go.id. Reaksi pasar yang diproksikan dengan abnormal return pada perusahaan yang melakukan aktivitas akuisisi pada tahun 2014-2018 menjadi obyek penelitian. Peristiwa yang mengandung informasi akan mengakibatkan pasar akan bereaksi. Purba (2017) meyatakan bahwa peristiwa bisa disebut sebagai kejutan atau juga hal yang tidak diharapkan terjadi. Indikator lain yang juga dapat mengukur reaksi pasar adalah dan trading volume activity. Tahapan yang dapat dilakukan dalam mengukur abnormal return ialah dengan mencari return saham individu yang sesungguhnya (actual return).

$$
\mathrm{R}_{\mathrm{it}}=\frac{P-P-1}{P-1}
$$

Keterangan :

$\mathrm{Pt} \quad=$ Harga sekuritas dihari ke-t

$\mathrm{Pt}_{-1} \quad=$ Harga sekuritas dihari ke $\mathrm{t}-1$

$\mathrm{R}_{\mathrm{it}} \quad=$ Return dihari ke- $\mathrm{t}$

Setelah melakukan perhitungan terhadap actual return, tahap berikutnya adalah melakukan perhitungan terhadap market return dengan rumus berikut:

$$
\mathrm{R}_{\mathrm{m}, \mathrm{t}}=\frac{h_{\mathrm{h}}-h_{\mathrm{h}}-1}{h_{\mathrm{i}}-1} .
$$

Keterangan :

$\mathrm{R}_{\mathrm{m}, \mathrm{t}} \quad=$ Market return pada hari ke- $\mathrm{t}$

$\mathrm{IHSG}_{\mathrm{t}}=$ IHSG harian pada hari ke-t

$\mathrm{IHSG}_{\mathrm{t}-1}=\mathrm{IHSG}$ harian pada hari ke $\mathrm{t}-1$

Model yang digunakan dalam penelitian ini adalah menggunakan market adjusted return, penggunaan model tersebut memandang bahwasanya untuk mengestimasi return sekuritas ialah dengan mengukur return indeks pasar pada 
saat tersebut, sehingga return sekuritas yang diestimasi sama dengan indeks pasarnya.

Langkah selanjutnya adalah dengan menghitung abnormal return dengan rumus berikut.

$$
\mathrm{AR}_{\mathrm{it}}=\mathrm{R}_{\mathrm{it}}-\mathrm{E}\left(\mathrm{R}_{\mathrm{it}}\right)
$$

Keterangan :

$\mathrm{R}_{\mathrm{it}} \quad=$ Return Individual sekuritas i sampai $\mathrm{t}$

$\mathrm{E}\left(\mathrm{R}_{\mathrm{it}}\right) \quad=$ Return ekspektasi sekuritas ke-i pada periode estimasi ke-t

$\mathrm{AR}_{\mathrm{it}} \quad=$ Abnormal return saham i pada periode peristiwa ke- $\mathrm{t}$

Perhitungan selanjutnya adalah dengan mencari rata-rata abnormal return dengan rumus berikut:

$$
\text { AARit }=\frac{\sum_{[-1}^{n} A}{n}
$$

Keterangan :

$\mathrm{AAR}_{\text {it }} \quad=$ Rata-rata abnormal return sekuritas i pada hari ke-t

$\mathrm{n} \quad=$ Sampel

$\mathrm{AR}_{\mathrm{it}} \quad=$ Abnormal return

Penggunaan teknik purposive sampling memiliki tujuan untuk menentuan jumlah sampel yang sesuai dengan kriteria tertentu seperti perusahaan yang melakukan aktivitas akuisisi pada periode 2014-2018 dan terdaftar di Bursa Efek Indonesia (BEI). Perusahaan tidak melakukan aksi korporasi selain akuisisi selama periode event window yaitu lima hari sebelum, hari $\mathrm{h}$ dan lima hari setelah pengumuman akuisisi. Saham aktif diperjualbelikan,. Perusahaan memiliki data yang diperlukan dalam penelitian seperti: tanggal pengumuman akuisisi yang digunakan dalam event date $\left(\mathrm{t}_{0}\right)$, harga saham penutup harian perusahaan yang melakukan aktivitas akuisisi dalam periode pengamatan dan IHSG harian.

Tabel 2.

\section{Penentuan Sampel Penelitian}

\begin{tabular}{lc}
\hline \multicolumn{1}{c}{ Keterangan } & Jumlah \\
\hline Perusahaan melaporkan aktivitas akuisisi ke KPPU periode 2014-2018 & 335 \\
Perusahaan tidak terdaftar di BEI & $(269)$ \\
Perusahaan tidak aktif & $(3)$ \\
Perusahaan tidak memiliki data yang dibutuhkan dalam penelitian & $(8)$ \\
Perusahaan yang sesuai dengan kriteria & $\mathbf{5 5}$ \\
\hline Sumber
\end{tabular}

Sumber :Data diolah, 2019

55 perusahaan adalah jumlah sampel yang sesuai dengan kriteria, namun lima diantaranya terindikasi memiliki data outliers sehigga harus dihapuskan dari sampel karena apabila tetap digunakan akan meghasilkan data yang bias dan memungkinkan terjadinya kesalahan dalam interpretasi dan mengampil sebuah simpulan, Sehingga sampel yang dipakai hanya 50 perusahaan saja dengan jumlah data sampel sebanyak 550 (50 perusahaan dikalikan 11 hari periode pengamatan peristiwa).

Metode penelitian menggunakan data sekunder yang didapat di web resmi www.kppu.go.id untuk memperoleh informasi perusahaan yang menggunakan 
strategi akuisisi dan juga situs Bursa Efek Indonesia yang dapat diakses di www.sahamok.com, www.idx.co.id dan www.finance.yahoo.com.

Hasil data yang di peroleh dalam uji beda rata-rata sampel berpasangan kemudian diproses melalui beberapa tahap analisis dengan bantuan program aplikasi untuk analisis statistik yaitu Statistical Package for Service Solution (SPSS). Pengujian dimulai dari analisis statistik deskriptif dengan cara menjelaskan atau mendeskripsikan sebuah data yang telah tersedia sebagaimana adanya tanpa memiliki maksud untuk menyimpulkan secara generalisasi atau umum (Sugiyono, 2017:147), uji normalitas dan juga uji hipotesis

\section{HASIL DAN PEMBAHASAN}

Tahap yang dilakukan sebelum memperoleh rata-rata abnormal return adalah menghitung actual return, market return atau expected return, abnormal return untuk setiap sekuritas selama event window. Perhitungan pertama dilakukan untuk mendapatkan actual return yaitu dengan menggunakan harga saham penutupan untuk setiap sekuritas selama event window.

Tabel 3.

Actual Return Selama Event Window

\begin{tabular}{ccccc}
\hline Hari ke- & Positif & Nol & Negatif & Total \\
\hline $\mathrm{t}-5$ & 11 & 14 & 25 & 50 \\
$\mathrm{t}-4$ & 20 & 10 & 20 & 50 \\
$\mathrm{t}-3$ & 16 & 12 & 22 & 50 \\
$\mathrm{t}-2$ & 16 & 12 & 22 & 50 \\
$\mathrm{t}-1$ & 13 & 16 & 21 & 50 \\
$\mathrm{t} 0$ & 16 & 13 & 21 & 50 \\
$\mathrm{t}+1$ & 24 & 8 & 18 & 50 \\
$\mathrm{t}+2$ & 17 & 9 & 24 & 50 \\
$\mathrm{t}+3$ & 22 & 8 & 20 & 50 \\
$\mathrm{t}+4$ & 15 & 14 & 21 & 50 \\
$\mathrm{t}+5$ & 20 & 11 & 19 & 50 \\
Total & 190 & 127 & 233 & 550 \\
\hline
\end{tabular}

Sumber: Data diolah, 2019

Tabel 3. menjelaskan hasil actual return yang tersebar dalam nilai positif atau kenaikan dimana harga sekuritas ke-i dihari ke-t lebih tinggi daripada harga saham dihari ke t-1. Actual return dengan nilai nol berarti harga saham hari ke-t memiliki nilai yang serupa dengan harga saham dihari ke t-1. Actual return negatif berarti terjadi penyusutan atau penuruna dimana harga saham pada sekuritas ke-i pada hari ke-t memiliki nilai yang lebih kecil daripada harga saham di hari ke t- 1 .

Nilai actual return dalam rentang waktu 11 hari di dominasi oleh actual return dengan nilai negatif, yang lebih jelasnya sebanyak 233 actual return atau sebanyak 42,36 persen. Actual return positif sebanyak 190 atau 34,55 persen, sedangkan actual return bernilai nol sebanyak 127 atau 23,09 persen. Tingginya 
jumlah actual return yang bernilai negatif megindikasikan bahwa selama periode pengamatan didominasi dengan penurunan harga.

Penurunan harga didominasi pada hari sebelum pengumuman akuisisi yang ditandai dengan didominasinya rata-rata actual return dengan nilai negatif yaitu pada hari kelima ( $t-5)$ sebesar $-0,00185$, dihari kedua ( $t$-2) sebesar - 0,00044 serta hari pertama (t-1) sebesar $-0,00164$.

Tabel 4.

Rata-Rata Actual Return Dalam Event Window

\begin{tabular}{cc}
\hline Hari ke- & Rata-rata Actual Return \\
\hline t-5 & $-0,00185$ \\
t-4 & 0,00071 \\
t-3 & 0,00051 \\
t-2 & $-0,00044$ \\
t-1 & $-0,00164$ \\
t0 & 0,00365 \\
t+1 & 0,00700 \\
t+2 & $-0,00158$ \\
t+3 & 0,00250 \\
t+4 & $-0,00064$ \\
t+5 & 0.00195 \\
\hline
\end{tabular}

Sumber: Data diolah, 2019

Tabel 4. serta Gambar 1. menunjukan bahwa rata-rata actual return di hari ke lima sebelum pengumuman akuisisi bernilai negatif yaitu -0.00185 kemudian dihari keempat (t-4) mengalami kenaikan kearah positif menjadi 0,00071 kemudian turun kembali di hari (t-3) sebesar 0,00051 hingga hari pertama (t-1) menjadi 0,00164 . Hari diumumknnya akuisisi $(\mathrm{t} 0)$ dan juga hari pertama $(\mathrm{t}+1)$ rata-rata actual return kembali mengalami kenaikan menjadi 0,00365 dan puncakya mencapai 0,00700. Hari kedua $(\mathrm{t}+2)$ hingga hari kelima $(\mathrm{t}+5)$ pergerakan actual return cenderung mengalami fluktuasi. Dimana pada $(\mathrm{t}+2)$ turun kemudian meningkat di hari $(t+3)$ kemudian turun di hari ke $(t+4)$ dan selanjutnya meningkat lagi dihari ke $(\mathrm{t}+5)$.

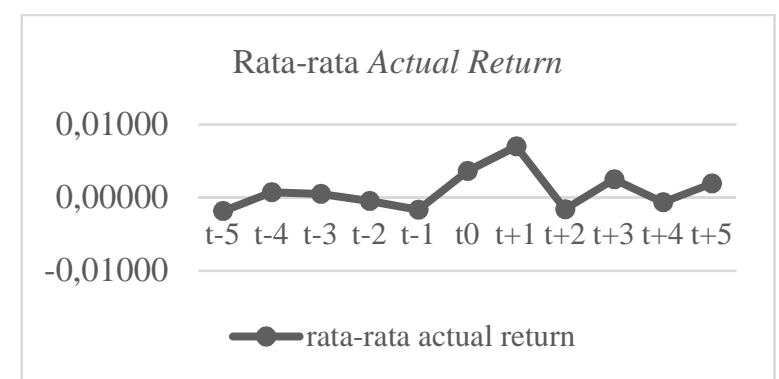

Gambar 1. Grafik Rata-rata Actual Return Selama Event Window Sumber : Data diolah, 2019 
Setelah rata-rata actual return diketahui, maka selanjutnya dilakukan perhitunga expected return yang memakai metode market - adjusted return yang berarti bahwa untuk mengestimasi return suatu sekuritas, penduga terbaiknya adalah dengan memakai market return di hari tersebut, sehingga expected return sama dengan market return-nya.

Tabel 5.

Rata-Rata Expected Return Selama Event Window

\begin{tabular}{cc}
\hline Hari ke- & Rata-rata Expected Return \\
\hline $\mathrm{t}-5$ & $-0,00187$ \\
$\mathrm{t}-4$ & 0,00046 \\
$\mathrm{t}-3$ & 0,00044 \\
$\mathrm{t}-2$ & $-0,00081$ \\
$\mathrm{t}-1$ & $-0,00139$ \\
$\mathrm{t} 0$ & 0,00219 \\
$\mathrm{t}+1$ & 0,00133 \\
$\mathrm{t}+2$ & $-0,00043$ \\
$\mathrm{t}+3$ & $-0,00070$ \\
$\mathrm{t}+4$ & 0,00087 \\
$\mathrm{t}+5$ & 0,00199 \\
\hline
\end{tabular}

Sumber: Data diolah, 2019

Tabel 5. dan Gambar 2. menjelaskan bahwa hari kelima (t-5) sebelum pengumuman akuisisi diperoleh nilai expected return yang negatif. Peningkatan kearah positif terjadi pada hari keempat $(\mathrm{t}-4)$ tetapi penurunan terjadi kembali hingga hari pertama $(\mathrm{t}-1)$.

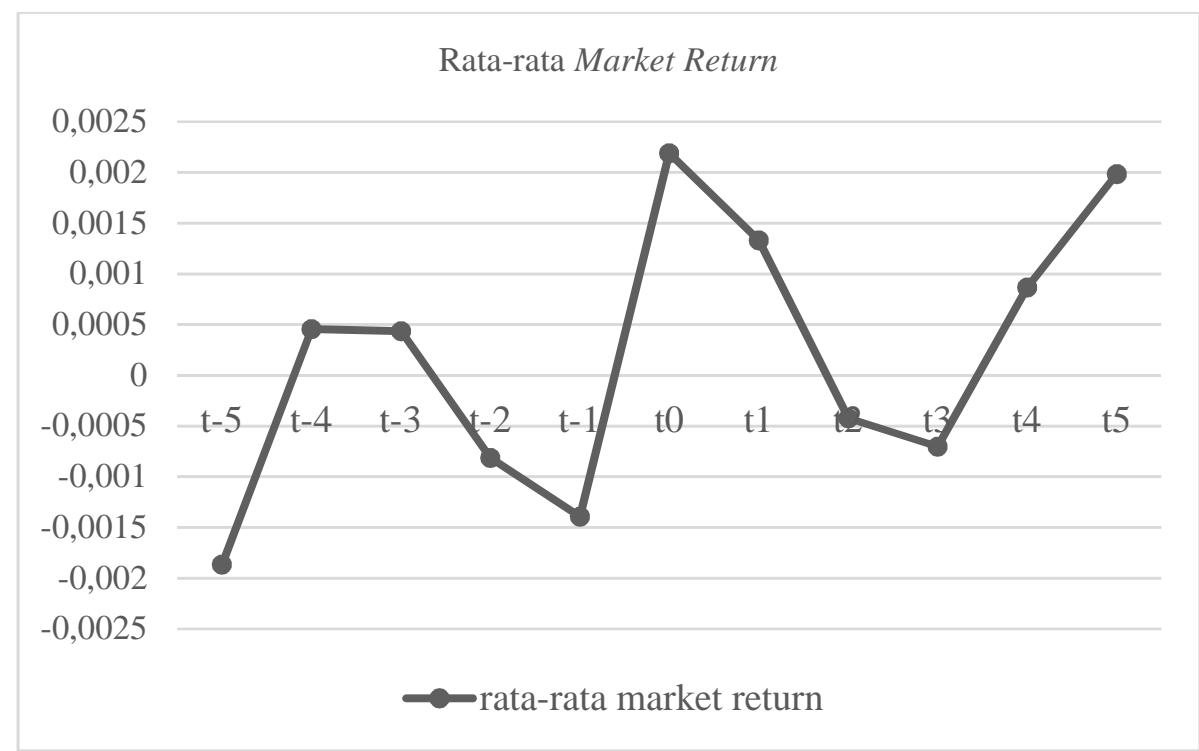

Gambar 2. Grafik Rata-rata Expected Return Selama Event Window Sumber: Data diolah, 2019

Hari diumumkannya akuisisi, expected return kembali mengalami peningkatan yang signifikan sehingga expected return bernilai positif. Peningkatan 
tersebut kemudian megalami penurunan dihari pertama setelah diumumkannya akuisisi hingga di hari ke tiga $(\mathrm{t}+3)$ sehingga memperoleh nilai expected return yang negatif. Expected return kembali meningkat kearah yang positif dihari keempat $(\mathrm{t}+4)$ serta kelima $(\mathrm{t}+5)$.

Tabel 6.

Rata-Rata Abnormal Return Selama Event Window

\begin{tabular}{cc}
\hline Hari ke- & AAR \\
\hline $\mathrm{t}-5$ & 0,00001 \\
$\mathrm{t}-4$ & 0,00025 \\
$\mathrm{t}-3$ & 0,00008 \\
$\mathrm{t}-2$ & 0,00038 \\
$\mathrm{t}-1$ & $-0,00025$ \\
$\mathrm{t} 0$ & 0,00146 \\
$\mathrm{t}+1$ & 0,00567 \\
$\mathrm{t}+2$ & $-0,00115$ \\
$\mathrm{t}+3$ & 0,00320 \\
$\mathrm{t}+4$ & $-0,00150$ \\
$\mathrm{t}+5$ & $-0,00004$ \\
\hline
\end{tabular}

Sumber : Data diolah, 2019

Tabel 6. dan Gambar 3. menujukan bahwa rata-rata abnormal return selama event window mengalami pergerakan yang berfluktuaktif. Fluktuasi rata-rata abnormal return mengindikasikan bahwa pasar bereaksi akibat dari adanya kandungan informasi yang cukup dalam pengumuman pengumuman akuisisi.

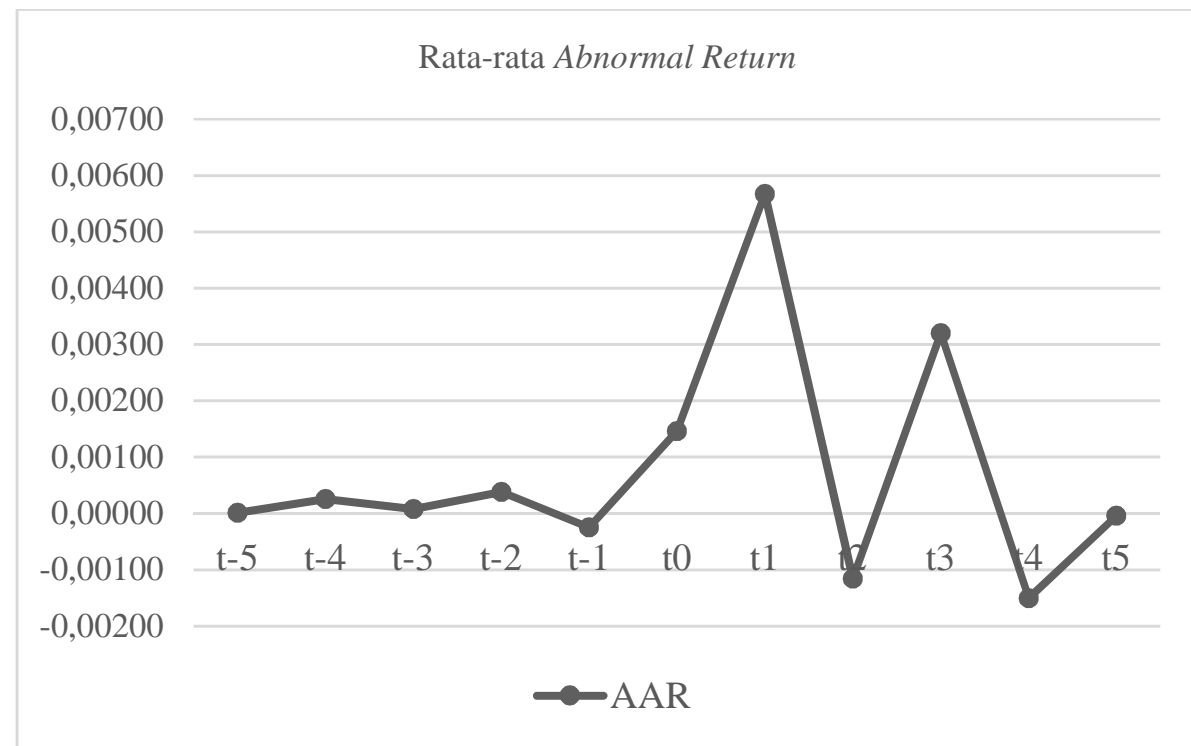

\section{Gambar 3. Grafik Pergerakan Rata-rata Abnormal Return Selama Event Window}

Sumber : Data diolah, 2019

Rata-rata abnormal return positif menunjukan reaksi pasar yang positif dan terjadi dihari ke $\mathrm{t}-5$, dihari ke $\mathrm{t}-4$, dihari ke $\mathrm{t}-3$, dihari ke $\mathrm{t}-2$, dihari pengumuman t0, dihari ke $\mathrm{t}+1$ dan dihari ke $\mathrm{t}+3$. Rata-rata abnormal return negatif yaitu dihari 
ke $\mathrm{t}-1$, dihari ke $\mathrm{t}+2$, dihari ke $\mathrm{t}+4$ dan dihari ke $\mathrm{t}-5$ berarti bahwa pasar bereaksi negatif. Rata-rata abnormal return paling tinggi terdapat dihari ke $\mathrm{t}+1$ dengn hasil sebesar 0,00567, selain itu rata-rata abnormal return terkecil terjadi di hari ke $\mathrm{t}+4$ dengan hasil sebesar $-0,00150$.

Sebelum pengumuman akuisisi rata-rata abnormal return cenderung bernilai positif sampai diumumkannya akuisisi. Hal tersebut mengindikasikan bahwa terjadi kebocoran informasi yang memicu minat investor untuk melakukan investasi. Hari pengumuman akuisisi ( $\mathrm{t} 0$ ) hingga hari pertama setelah pengumuman akuisisi $(\mathrm{t}+1)$ terdapat kenaikan rata-rata abnormal return hingga mencapai angka 0,00567. Peningkatan yang paling tinggi diantara hari-hari lain selama periode pengamatan menunjukan bahwa terdapat reaksi pasar yang percaya bahwa pengumuman akuisisi memiliki berita baik sehingga mampu menimbulkan sebuah return yang menguntungkan investor.

Peningkatan dihari ke $\mathrm{t}+1$ nyatanya tidak bertahan lama karena dihari ke $\mathrm{t}+2$ penurunan drastis terjadi hingga mencapai $-0,00115$. Penurunan yang terjadi setelah pengumuman megindikasikan bahwa pasar cenderung ragu dengan kandungan informasi dari pengumuman akuisisi. Hal tersebut dibuktikan pada pergerakan ratarata abnormal return setelah dipublikasikannya akuisisi yang sangat berfluktuatif dan sebagian besar bernilai negatif. Penurunan terjadi pada hari ke $t+2$, kemudian mengalami kenaikan pada hari ke-t+3 hingga menyentuh titik positif, selanjutnya kembali mengalami penurunan ke tingkat negatif pada hari ke- $t+4$ dan kemudian terjadi peningkatan kembali pada hari ke $t+5$ namun masih dalam tingkat yang negatif. Pergerakan yang sangat berfluktuatif juga menandakan bahwa informasi yang tersedia nyatanya belum tersebar secara merata, sehingga para investor cenderung ragu untuk mengambil sebuah keputusan investasi. Ketidak konsistensian reaksi pasar setelah pengumuman akuisisi menyebabkan investor harus mengamati kandungan informasi yang terdapat pada pengumuman akuisisi dengan rentang waktu yang lebih lama, karena investor harus menilai tujuan dilakukannya akuisisi agar tidak salah ketika mengambil sebuah keputusan investasi.

Tabel 7. memaparkan nilai terkecil, nilai terbesar, standar deviasi serta nilai rata-rata abnormal return dalam event window.

Perhitungan nilai terkecil selama event window adalah -0,0847 yang didapat oleh PT. Japfa Comfeed Indonesia, Tbk pada hari t-2, sedangkan nilai maksimumnya yaitu 0,1465 didapat oleh PT. Medco Energi International, Tbk pada hari ke $\mathrm{t}+3$. Selanjutnya nilai mean rata-rata dari ke-11 hari periode pengamatan ialah 0,00074 dengan rata-rata standar deviasi sebesar 0,0222478.

Untuk mengetahui sebaran data yang digunakan dan nantinya akan menunjukan apakah data tersebut berdistribusi normal atau tidak,maka diperlukan sebuah pengujian yang disebut uji normalitas (Sugiyono, 2017: 232).

Tabel 8. menjelaskan bahwa rata-rata abnormal return sebelum akuisisi ialah $0,200>0,005$ atau dapat dikatakan data berdistribusi normal. Berbeda dengan ratarata abnormal return dihari sesudah akuisisi yaitu $0,001<0,005$ atau dapat dikatakan bahwasanya data yang digunakan dalam penelitian tidak berdistribusi normal sehingga dengan begitu dapat ditarik simpulan bahwa hasil uji normalitas 
ialah data tidak berdistribusi normal. Hal tersebut mengakibatkan dalam proeses uji selanjutnya menggunakan uji wilcoxon signed rank test.

Tabel 7.

Statistik Deskriptif Abnormal Return Selama Event Window

\begin{tabular}{cccccc}
\hline Hari ke & N & Minimum & Maximum & Mean & $\begin{array}{c}\text { Std. } \\
\text { Deviation }\end{array}$ \\
\hline t-5 & 50 & $-0,0716$ & 0,0530 & 0,00001 & 0,0186103 \\
t-4 & 50 & $-0,0847$ & 0,0680 & 0,00025 & 0,0257026 \\
t-3 & 50 & $-0,0375$ & 0,0810 & 0,00008 & 0,0192437 \\
t-2 & 50 & $-0,0390$ & 0,0604 & 0,00038 & 0,0174878 \\
t-1 & 50 & $-0,0450$ & 0,0593 & $-0,00025$ & 0,0169033 \\
t0 & 50 & $-0,0498$ & 0,0902 & 0,00146 & 0,0241195 \\
t+1 & 50 & $-0,0423$ & 0,1465 & 0,00567 & 0,0281947 \\
t+2 & 50 & $-0,0539$ & 0,0435 & $-0,00115$ & 0,0186817 \\
t+3 & 50 & $-0,0319$ & 0,1173 & 0,00320 & 0,0272893 \\
t+4 & 50 & $-0,0613$ & 0,1359 & $-0,00150$ & 0,0279869 \\
t+5 & 50 & $-0,0457$ & 0,0485 & $-0,00004$ & 0,0205064 \\
Valid N (listwise) & 50 & & & & \\
\end{tabular}

Sumber: Data diolah, 2019

Tabel 8.

Uji Normalitas Rata-rata Abnormal Return Selama Event Window

\begin{tabular}{cccccc}
\hline Variabel & Jumlah & $\begin{array}{c}\text { Kolmogorov- } \\
\text { Smirnov Z }\end{array}$ & $\begin{array}{c}\text { Asym,Sig } \\
(\text { 2-Tailed) }\end{array}$ & $\boldsymbol{\alpha}$ & Keterangan \\
\hline $\begin{array}{c}\text { AAR } \\
\text { Sebelum } \\
\text { AAR }\end{array}$ & 50 & 0,070 & 0,200 & 0,05 & Distribusi Normal \\
$\begin{array}{c}\text { Sesudah } \\
\text { Sumber: } \text { Data diolah, } 2019\end{array}$ & 50 & 0,167 & 0,001 & 0,05 & Distribusi Tidak Normal \\
\hline
\end{tabular}

Tabel 9.

Uji Wilcoxon Signed Rank Test Rata-rata Abnormal Return Selama Event

Window

\begin{tabular}{cccccc}
\hline Variabel & Jumlah & Nilai Z & $\begin{array}{c}\text { Asym,Sig (2- } \\
\text { Tailed) }\end{array}$ & $\boldsymbol{\alpha}$ & Keterangan \\
\hline $\begin{array}{l}\text { Rata-Rata } \\
\text { Abnormal } \\
\begin{array}{l}\text { Return } \\
\text { Sebelum- }\end{array}\end{array}$ & 50 & $-1,009$ & 0,313 & 0,05 & Tidak \\
$\begin{array}{l}\text { Sesudah } \\
\text { Sumber: } \text { Data diolah, } 2019\end{array}$ & & & & Signifikan \\
\end{tabular}

Tabel 9. menjelaskan bahwa nilai probabilitasnya adalah $0,313>0,05$ yang menunjukan bahwa tidak adanya perbedaan yang signifikan. Perolehan hasil tersebut dapat di simpulkan bahwa $\mathrm{H}_{1}$ ditolak dan $\mathrm{H}_{0}$ diterima, dalam artian bahwa tidak terdapat perbedaan reaksi pasar sebelum dan sesudah pengumuman akuisisi. 
Tabel 10.

Rangkuman Hasil Analisis

\begin{tabular}{cccccc}
\hline Variabel & Jumlah & Rata-Rata & $\begin{array}{c}\text { Asym,Sig (2- } \\
\text { Tailed) }\end{array}$ & $\boldsymbol{\alpha}$ & Keterangan \\
\hline $\begin{array}{c}\text { AAR } \\
\text { Sebelum } \\
\text { AAR }\end{array}$ & 50 & 0,0001 & & & Tidak \\
Sesudah & 50 & 0,0012 & 0,313 & 0,05 & Signifikan \\
\hline
\end{tabular}

Sumber: Data diolah, 2019

Tabel 10. menunjukan rata-rata abnormal return 0,0001 dihari sebelum diumumknnya akuisisi dan rata-rata abnormal return 0,0012 di hari sesudah diumumkanya akuisisi. Teori sinyal memaparkan bahwasanya sinyal yang baik tercermin dari perbedaan nilai rata-rata abnormal return sebelum dan sesudah dipublikasikannya pengumuman akuisisi. Rata-rata abnormal return selama event window sangatlah kecil dan menunjukan bahwa pengumuman akuisisi memiliki sinyal yang cukup baik sehingga pasar bereaksi tetapi reaksi yang terjadi tidak signifikan karena informasi yang tersedia tidak terlalu mempengaruhi persepsi investor dalam melakukan investasi.

Perbedaan yang sangat kecil juga mengakibatkan hasil uji hipotesis memperoleh nilai asym sig sebesar 0,313 > 0,05 yang menyebabkan hipotesis penelitian tidak diterima. Hasil tersebut menandakan bahwasanya tidak terdapat perbedaan reaksi pasar yang signifikan sebelum dan sesudah dipublikasikannya pengumuman akuisisi. Perbedaan reaksi pasar yang tidak signifikan dikarenakan ketidaktahuan investor akan motif perusahaan dalam melaksanakan akuisisi, apakah termasuk motif ekonomi (perusahaan target memiliki keuggulan kompetitif sehingga memberikan sinergi positif) ataupun motif non ekonomi (perusahaan dalam keadaan lemah dari segi keterampilan dan juga modal). Ketidaktahuan investor akan motif perusahaan melakukan akuisisi mengakibatkan investor ragu untuk mengambil sebuah keputusan investasi.

Penyebab lainnya adalah karena pengumuman akuisisi nyatanya bukanlah sebuah pengumuman yang mengejutkan bagi investor karena pada umumnya akuisisi suatu perusahaan telah dimasukan pada agenda rapat umum pemegang saham (RUPS) sehigga dapat dikatakan bahwasanya informasi terkait dilaksanakannya akuisisi tidak tersebar secara merata atau dengan kata lain informasi mengalami kebocoran.

Hasil penelitian tersebut didukung oleh peneliti-peneliti sebelumnya seperti Febyanti (2014) yang menganggap bahwa pengumuman akuisisi tidak menunjukan reaksi yang signifikan diantara sebelum dan sesudah dipublikasikannya pengumuman yang disebabkan karena adanya keraguan investor untuk mengambil keputusan. Sihombing dan Kamal (2016) menunjukan hasil bahwa akuisisi ataupun merger tidaklah mengakibatkan pengaruh ekonomis bagi perusahaan yang ditunjukan dari tidak adanya perbedaaan abnomal return yang signifikan. Khoirulllah (2016) menemukan bahwasanya pengumuman merger dan akuisisi direspon biasa-biasa saja oleh investor, sehingga investor tidak memiliki harapan untuk mendapatkan abnormal return pada saat diumumkannya akuisisi dan merger. Hal tersebut dikarena ketidaktahuan investor akan motif perusahaan melakukan 
akuisisi. Hasil serupa itemukan juga oleh Kyriazopoulos (2016), Khairudin dan Wulandari (2017), Mall dan Gupta, (2018), Shah dan Arora (2014), dan Sachdeva et al. (2015).

Hasil penelitian yang diperoleh nyatanya belum sejalan dengan teori efisiensi pasar, karena informasi yang dipublikasikan belum mampu membuat pasar bereaksi secara signifikan yang diproksikan dari abnormal return. Teori efisiensi pasar diukur melalui informasi-informasi yang tersedia telah tercermin pada harga sekuritas. Abnormal return yang bernilai positif atau negatif di hasil penelitian menunjukan bahwa pasar dalam bentuk efisien setengah kuat. Hal tersebut dikarenakan informasi yang tersedia tidak secara penuh terkandung pada harga saham di tanggal pengumuman akuisisi, sehingga pasar masih ragu akan motif dari aktivitas akuisisi dari suatu perusahaan.

Investor harus mengetahui bahwa tidak semua informasi dalam pasar modal adalah informasi berharga, sehingga para investor perlu untuk segera menganalisis dan memilah informasi-informasi tersebut untuk dapat dijadikan acuan atau pertimbangan dalam membuat keputusan investasi. Investor juga harus mengetahui motif perusahaan dalam melakukan akuisisi agar investor terhindar dari risiko yang akan terjadi setelah pengumuman akuisisi di publikasikan.

\section{SIMPULAN}

Informasi akuisisi yang masuk ke pasar memiliki sinyal yang cukup baik sehingga menimbulkan reaksi pasar, namun reaksi yang terjadi nyatanya tidak signifikan sehingga hipotesis ditolak. Hasil tersebut berarti bahwa secara statistik tidak terdapat perbedaan reaksi pasar yang sigifikan sebelum dan sesudah dipublikasikannya pengumuman akuisisi karena informasi yang tersedia tidak memiliki kandungan informasi yang cukup untuk memengaruhi persepsi investor dalam melakukan sebuah investasi. Penyabab lainnya dikarenakan ketidaktahuan investor akan motif perusahaan melakukan akuisisi sehingga investor masih ragu untuk mengambil keputusan dalam investasi.

Penelitian selanjutnya, disarankan memakai indikator lain seperti TVA (trading volume activity) dalam menguji reaksi pasar. Pengujian abnormal return selanjutnya juga dapat memakai metode selain market adjusted model seperti market model ataupun dengan menggunakan metode mean-adjusted model agar hasilnya lebih akurat. Penambahan jumlah pengamatan juga diperlukan agar semakin menggambarkan reaksi pasar dari pengumuman akuisisi.

Bagi para investor disarankan untuk tidak terlalu terburu-buru ketika akan melakukan sebuah aktivitas jual beli saham hanya karena berpatokan pada satu informasi, karena nyatanya tidak semua informasi yang masuk di pasar modal memiliki informasi berharga, sehingga megakibatkan investor harus segera menganalisis informasi-informasi yang relevan khususnya motif perusahaan melakukan akuisisi untuk digunakan sebagai pertimbangan ketika akan membuat keputusan investasi. 


\section{REFERENSI}

Adnan, A., \& Hossain, A. (2016). Impact of M\&A Announcement on Acquiring and Target Firm's Stock Price: An Event Analysis Approach. International Journal of Finance and Accounting, 5(5), 228-232. https://doi.org/10.5923/j.ijfa.20160505.02

Adnyani, I. P., \& Gayatri. (2018). Analisis Reaksi Pasar Terhadap Pengumuman Akuisisi Pada Perusahaan Akuisitor Yang Terdaftar di BEI. E- Jurnal Akuntansi Universitas Udayana, 23(3), 1870-1899.

Andriani, N. L. A. D., \& Purbawangsa, I. B. A. (2016). Dampak Akuisisi PT Agung Podomoro Land, Tbk Terhadap Reaksi Pasar Sektor Properti Bursa Efek Indonesia. E-Jurnal Manajemen Unud, 5(1), 414-442.

Dananjaya, I. B. G., \& Wiagustini, N. Lu. P. (2015). Studi Komparatif Abnormal Return Sebelum dan Sesudah Merger Pada Perusahaan di BEI. E-Jurnal Manajemen Unud, 4(4), 1085-1099.

Diaw, A. (2014). the Effect of Mergers and Acquisitions on Shareholder Wealth: The Case of European Banks. International Journal of Financial Management, 4(4), 1-20.

Dr. Devarajappa S. (2018). Market Reaction toward the Bank Mergers in India : An Event Study of Selected Merged Banks. SMJV'S CKSV Institute of Management, 8(1), 19-31.

Elad, F. L., \& Bongbee, N. S. (2017). Event Study on the Reaction of Stock Returns to Acquisition News. International Finance and Banking, 4(1), 33. https://doi.org/10.5296/ifb.v4i1.10409

Fahmi, I. (2012). Manajemen Investasi Teori dan Soal Jawab. Jakarta: Salemba Empat.

Fama, E. (1970). Efficient Capital Markets - A review of theory and empirical work. Journal of Finance, 25(2).

Febyanti, S. (2014). Analisis Reaksi Pasar Sebelum dan Sesudah Pengumuman Akuisisi PT. Hanjaya Mandala Sempoerna Tbk. Jurnal Ilmu Manajemen, 2(1), 104-113.

Geekiyanage, G., \& Jahfer, A. (2017). Stock Price Reaction To Merger and Acquisition Announcement: Evidence From Colombo Stock Market. Proceedings of 7th International Symposium, SEUSL, 2017(December), 1928.

Israil, S., \& Khan, N. (2016). The Impact of Merger and Acquisition on Karachi 
Stock Exchange-Testing Semi-Strong Efficient Market Hypothesis. Sarhad Journal of Management Sciences, 2(2), 139-156. https://doi.org/10.31529/sjms.2016.2.2.4

Jogiyanto, H. (2017). Teori Portofolio dan Analisis Investasi (Kesebelas). Yogyakarta: BPFE.

Kariuki, B., Muturi, W., \& Kiragu, D. (2016). Stock Market Reaction to Mergers and Acquisitions Announcements in Emerging Markets. Evidence from Mergers and Acquisitions Firms Listed in Eastern Africa Securities Markets. Research Journal of Finance and Accounting Www.iiste.org ISSN, 7(22), 130141. Retrieved from www.iiste.org

Khairudin, M., \& Wulandari, T. R. (2017). Merger, Akuisisi, dan Kinerja Saham Perusahaan Di Bursa Efek Indonesia (BEI). Jurnal Akuntansi Dan Bisnis, 17(1), 27-37.

Khoirulllah, A. L. (2016). Analisis Dampak Pengumuman Akuisisi terhadap Return Saham Perusahaan Akuisitor dan Yang Diakuisi ( Studi Empiris Pada Perusahaan Akuisitor dan yang Diakuisisi yang Terdaftar di BEI Tahun 20102013 ). Artikel Ilmiah Mahasiswa, 1-8.

Komisi Pengawas Persaingan Usaha. (n.d.). Daftar Perusahaan yang Melakukan Merger dan Akuisisi di Indonesia Tahun 2014-2018. Retrieved from www.kppu.go.id. Diakses pada 1 Agustus 2019

Kyriazopoulos, G. (2016). Wealth effects from banks mergers and acquisitions in Eastern Europe. International Journal of Economics and Financial Issues, $6(2), 588-595$.

Larasati, P., \& Wirama, D. G. (2018). Respon Pasar Terhadap Pengumuman Akuisisi pada Perusahaan Pengakuisisi yang Terdaftar di BEI Tahun 20132017. E-Jurnal Akuntansi, 507. https://doi.org/10.24843/eja.2018.v24.i01.p19

Malau, R., Wiagustini, L. P., \& Artini, L. G. S. (2017). Pengujian Reaksi Pasar Terhadap Peristiwa Merger dan Akuisisi Di Bursa Efek Indonesia (BEI). EJurnal Ekonomi Dan Bisnis Universitas Udayana, 6(9), 3325-3352.

Mall, Pinky; Gupta, K. (2019). Impact of Merger Announcements on Stock Returns of Acquiring Impact of Merger Announcements on Stock Returns of Acquiring Firms : Evidence From India. Journal of Commerce \& Accounting Research, 8(1), 46-53.

Munthe, K. (2016). Perbandingan Abnormal Return Dan Likuditas Saham Sebelum Dan Sedudah Stock Split: Studi Pada Perusahaan Yang Terdaftar Di Bursa 
Efek Indonesia. Jurnal Akutansi, 20(2), 254-266.

Presiden Republik Indonesia. Undang-undang No 8 Tahun 1995 Tentang Pasar Modal. , Pub. L. No. 8(1995).

Purba, T. (2017). Analisis Komparasi Abnormal Return Dan Volume Perdagangan Saham Atas Pemberlakuan Peraturan Pemerintah Nomor 1 Tahun 2014. Jurnal Riset Bisnis Dan Manajemen, 5(1), 55-72.

Rahman, Z., Ali, A., \& Jebran, K. (2018). The effects of mergers and acquisitions on stock price behavior in banking sector of Pakistan. The Journal of Finance and Data Science, 4(1), 44-54. https://doi.org/10.1016/j.jfds.2017.11.005

Rani, N., Yadav, S. S., \& Jain, P. K. (2015). Impact of Mergers and Acquisitions on Shareholders' Wealth in the Short Run: An Event Study Approach. VIKALPA The Journal for Decision Makers, 40(3), 293-312. https://doi.org/10.1177/0256090915600842

Reuters, T. (2014). Institute of Merger, Acquisition and Alliiances (IMAA) Analysis. Retrieved from http://imaa-institute.org/

Sachdeva, T., Sinha, N., \& Kaushik, K. P. (2015). Impact of merger and acquisition announcement on shareholders' wealth: An empirical study using event study methodology. Delhi Business Review $\square$, 16(2), 19-36.

Shah, P., \& Arora, P. (2014). M\&A Announcements and Their Effect on Return to Shareholders: An Event Study. Accounting and Finance Research, 3(2), 170190. https://doi.org/10.5430/afr.v3n2p170

Sihombing, N., \& Kamal, M. (2016). Analisis Pengaruh Pengumuman Merger dan Akuisisi Terhadap Abnormal Return Saham dan Kinerja Keuangan Perusahaan ( Studi pada perusahaan yang melakukan Merger dan Akuisisi pada Tahun 2011 dan terdaftar di Bursa Efek Indonesia ). Diponegoro Journal of Management, 5(3), 1-15.

Simarmata, D., \& Saifi, M. (2018). Analisis Perbandingan Return On Investment (ROI), Earning Per Shre (EPS), dan Abnormal Return Perusahaan Sebelum dan Sesudah Akuisisi (Studi pada Perusahaan di Bursa Efek Indonesia yang melakukan Akuisisi pada Tahun 2013). Jurnal Administrasi Bisnis (JAB)|Vol, 61(2), 194-201.

Singhvi, A. S., \& Patel, P. (2016). Impact of Merger Announcement on Selected Scripts of CNX Nifty Introduction: International Academic Journal of Ecoomics, 3(1), 35-47.

Sugiyono. (2017). Metode Penelitian Kuantitatif, Kualitatif dan R\&D. Bandung: 
E-Jurnal Manajemen, Vol. 9, No. 2, 2020 : 699-717

Alfabeta.

Tandelilin, E. (2010). Analisis Investasi dan Manajemen Portofolio (ketujuh). Yogyakarta: Kanisius.

Tarabay, M., \& Hammoud, J. (2017). Abnormal Returns to Shareholders of M\&A Participating Firms: Evidence from the Kuwaiti Stock Market. Journal of Business \& Financial Affairs, 6(2). https://doi.org/10.4172/21670234.1000259

Tarigan, J., Yenewan, S., \& Natalia, G. (2016). Merger dan Akuisisi: Dari Perspektif dan Strategis di Indonesia. Yogyakarta: Ekuilibria.

Wiagustini, N. L. P. (2014). Manajemen Keuangan. Denpasar: Udayana University Press. 